\title{
Synthesis and Characterization of Graft Copolymer Rice Straw Cellulose-Acrylamide Hydrogels Using Gamma Irradiation
}

\author{
D. Swantomo ${ }^{1,2^{\star}}$, Rochmadi ${ }^{3}$, K.T. Basuki ${ }^{1}$ and R. Sudiyo ${ }^{3}$ \\ ${ }^{I}$ Polytechnic Institute of Nuclear Technology, National Nuclear Energy Agency \\ Jl. Babarsari Kotak Pos 6101 YKBB, Yogyakarta 5528, Indonesia \\ ${ }^{2}$ Doctoral Program of Chemical Engineering Department, Gadjah Mada University \\ Jl. Grafika No 2, Bulaksumur, Yogyakarta 55281, Indonesia \\ ${ }^{3}$ Chemical Engineering Department, Gadjah Mada University \\ Jl. Grafika No 2, Bulaksumur, Yogyakarta 55281, Indonesia
}

\section{ARTICLE INFO}

Article history:

Received 16 January 2013

Received in revised form 3 June 2013

Accepted 21 June 2013

Keywords:

Rice straw cellulose

Acrylamide

Graft copolymerization

Gamma irradiation

Kinetics

\begin{abstract}
A B S T R A C T
Rice straw cellulose available as waste biomass was graft copolymerized with acrylamide monomer by simultaneous gamma irradiation as initiator. The effects of bleaching of cellulose and irradiation dose were evaluated. Evidence of grafting is obtained from comparison of Fourier Transfer Infrared (FTIR) of the cellulose and grafted cellulose. X-ray diffraction analysis shows that crystallinity was reduced through graft copolymerization. Kinetic investigations of the graft copolymerization were also carried out, and the rate constant parameter $\left(\mathrm{k}_{\mathrm{p}} / \mathrm{k}_{\mathrm{t}}^{0.5}\right)$ has been found to be $4.99221^{0.5} \cdot \mathrm{mol}^{-0.5} \cdot \mathrm{s}^{-0.5}$. The results show that for the same dose, grafting efficiency is higher with the bleached cellulose form than with the unbleached form. The grafting efficiency and the gel fraction increases with increasing total irradiation doses. At higher radiation doses crosslink density starts to increase considerably while swelling degree decreases with the increasing crosslink density.
\end{abstract}

\section{INTRODUCTION}

It is widely recognized that technologies which can economically convert biomass resources into commercially valuable materials are needed. Cellulose is a candidate among biomass resources as this organic raw material is abundant in nature, inexpensive, biodegradable and renewable. Indonesia is one of the largest rice-producing countries in the world; therefore, rice straw waste is abundant in the country. However, the material has only been utilized in low-value-added applications, for instance, as animal feed, as fuel, and in the production of chip board. In fact, much of rice straws produced is simply burned in the open. Greater value added could be attained if rice straw cellulose is used for producing high-performance materials. However, for that purpose, it is necessary to first modify the cellulose.

The main compounds in rice straw are cellulose, hemicelluloses, and lignin. Cellulose is a linear macromolecule consisting of (1-4) glycosidic linkages of $\beta$-D-glucopyranosyl monomers, and this

\footnotetext{
* Corresponding author.

E-mail address: deni@sttn-batan.ac.id
}

$\beta-(1-4)$ configuration contributes to its rigid structure and to the formation of aggregates through intra- or inter-molecular hydrogen bonds via hydroxyl groups [1,2]. By chemical modification of cellulose through graft copolymerization with synthetic monomers many different properties, including water absorbency [1], elasticity [3], ionexchange capabilities [4], thermal resistance and resistance to microbiological attack [5] can be improved. For economic and environmental purposes, the present work focuses on the use rice straw waste as a substrate for preparation of low cost hydrogels.

Cellulose from rice straw is a suitable candidate for the preparation of hydrogels by grafting or crosslinking reactions, as it has been shown to be a good precursor material for the preparation of hydrogels due to its great crosslinking and grafting ability in the presence of abundant hydroxyl $(-\mathrm{OH})$ groups [6-9]. However, the low swelling degree of cellulose and its poor mechanical properties have hampered the development of unmodified cellulose as stable hydrogels. Recently, there has been a growing interest in chemical modification of cellulose to 
improve its properties. Graft copolymerization is a widely used chemical modification method for cellulose in order to improve its properties $[1,2,4]$. Rice straw grafting with acrylonitrile can increase its wastewater adsorption capacity [10]. In recent years, a number of monomers have been grafted onto cellulose by copolymerization in order to improve swelling property, reduce production costs and ensure biodegradability. Those monomers include ethyl acrylate, styrene, allyldimethylhydantoin, and vinyl acetate, among others. Acrylamide is one of the favorite choices due to its excellent compatibility with cellulose, ease of preparation, non-carcinogenicity, low cost, biocompatibility, and biodegradability in nature.

Various initiation techniques, including chemical [5], photochemical [11], and high energy radiation [6] methods, have been used to activate or initiate the backbone cellulose polymer. Radiationinduced graft copolymerization in hydrogel preparation is one of the most promising methods because of its ease of handling at room temperature, deep penetration in polymer matrix, rapid and uniform formation of active sites for initiating grafting, and lack of need for chemical initiator. Generally, with the radiation technique, absorption of energy by the polymer's backbone initiates a free radical process. With chemical initiation, free radicals are brought forth by the decomposition of the initiator into fragments which then attack the base polymer leading to free radicals.

In the present study, the synthesis and characterization of graft-copolymer rice straw cellulose-acrylamide hydrogels using simultaneous gamma irradiation technique are studied. The chemical structure and crystallinity of the grafted hydrogels are investigated to confirm and monitor the structural changes induced by grafting of cellulose-acrylamide. It is necessary to consider the kinetics of graft copolymerization in order to elucidate the mechanism of the grafting process. The effect of irradiation doses on hydrogels characterization such grafting efficiency, gel fraction, crosslink density, and swelling degree in water are reported.

\section{EXPERIMENTAL METHODS}

\section{Preparation of cellulose from rice straw}

Rice straw was obtained from rice field in Bantul, Indonesia. Pure analysis-grade acrylamide monomer was obtained from Merck. Other chemicals used, namely sodium hydroxide, acetone, distilled water (aquadest), ethanol, and $\mathrm{H}_{2} \mathrm{SO}_{4}$, were of technical grade.
Rice straw was first crushed with a; disintegrator; afterwards, it was ground to 60-mesh size particles and cleaned prior to use. Cellulose pulp was made by soda process [1]. Bleaching of cellulose used the hydrogen peroxide process.

\section{Preparation of cellulose-acrylamide graft copolymerization by simultaneous gamma irradiation}

Cellulose was mixed with distilled water at $400 \mathrm{rpm}$ at room temperature for 1 hour. Acrylamide was added into the mixture for 8 hours. The mixture was then poured into a $250 \mathrm{~cm}^{3}$ aluminum tube which inner wall is covered with aluminum foil. Then, the tube was irradiated with gamma radiation using Gamma Chamber-40 with the desired total dose and dose rate. The resulting cellulose-acrylamide graft copolymer was then washed with aquadest and separated using centrifuge to remove ungrafted cellulose and homopolymers. The product was dewatered with ethanol and dried in a vacuum oven at $65^{\circ} \mathrm{C}$ for 24 hours. Based on weight data obtained from gravimetry, grafting efficiency was calculated using equation (1):

$$
\text { Grafting efficiency }=\frac{W_{h}-W_{S}}{W_{m}} \times 100 \%
$$

where $W_{h}$ is the weight of cellulose-acrylamide graft copolymer, $W_{s}$ is the weight of cellulose, and $W_{m}$ is the weight of acrylamide monomer.

\section{Characterization of cellulose-acrylamide graft copolymerization hydrogels}

Using FTIR (Fourier Transform Infrared) spectroscopic technique, sample characterization was carried out to follow the change in the functionality of cellulose as a result of grafting. The FTIR study of cellulose-acrylamide graft copolymers was done using a Thermo Nicolet Avatar FTIR spectrophotometer. XRD (X-ray diffraction) studies were performed under ambient conditions, using a Shimadzu XRD-6000 X-ray diffractometer. Percentage crystallinity $(\% \mathrm{Cr})$ and crystallinity index (C.I.) $[12,13]$ are calculated from equations (2) and (3).

$$
\% C r=\frac{I_{22}}{I_{22}+I_{18}} \times 100 \%
$$




$$
\% \text { C.I. }=\frac{I_{22}-I_{18}}{I_{22}}
$$

where $I_{22}$ and $I_{18}$ are the crystalline and amorphous intensities at $2 \theta$ scale close to $22^{\circ}$ and $18^{\circ}$ respectively.

For gel fraction measurement, the irradiated samples were extracted with aquadest using Soxhlet extractor for $8 \mathrm{~h}$ at ambient temperature. The insoluble fraction was dried at $60{ }^{\circ} \mathrm{C}$ for $3 \mathrm{~h}$. The gel fraction was then calculated using equation (4).

$$
\text { Gel fraction }=\frac{W_{1}}{W_{0}} \times 100 \%
$$

where $W_{0}$ is the initial weight of the sample and $W_{1}$ is the weight of the insoluble residue.

The crosslink density of irradiated samples was determined by using swelling technique according in conjunction with the Flory-Rhener theory $[14,15]$. The equilibrium swelling theory of Flory-Rhener proposed for sample polymer network is expressed in equation (5).

$$
\rho_{e}=\frac{\left[\ln \left(1-v_{2, s}\right)+v_{2, s}+\chi_{1}\left(v_{2, s}\right)^{2}\right] / V_{1}}{\left(v_{2, s}{ }^{1 / 3}-\frac{v_{2, s}}{2}\right)}
$$

where $\chi_{1}$ is the dimensionless Flory-Huggins polymer-solvent interaction term for cellulose-water $0.44, V_{1}$ is is the molar volume of solvent, and $v_{2, s}$ is the polymer volume fraction in the swollen state. In other words, $v_{2, s}$ is the amount of liquid which can be imbibed by the hydrogel, and it is expressed as the ratio of the polymer volume $\left(\mathrm{V}_{\mathrm{p}}\right)$ to the swollen gel volume $\left(\mathrm{V}_{\mathrm{g}}\right)$. It is also the reciprocal of the volumetric swollen ratio $(\mathrm{Q})$ which relates to the densities of the solvent $\left(\rho_{\mathrm{s}}\right)$ and polymer $\left(\rho_{\mathrm{p}}\right)$ and mass swollen ratio $\left(Q_{m}\right)$ as given by equation $(6)$.

$$
v_{2, \mathrm{~s}}=\frac{\mathrm{V}_{\mathrm{p}}}{\mathrm{V}_{\mathrm{g}}}=\mathrm{Q}^{-1}=\frac{1 / \rho_{\mathrm{p}}}{\mathrm{Q}_{\mathrm{m}} / \rho_{\mathrm{s}}+1 / \rho_{\mathrm{p}}}
$$

The Japanese Industrial Standard K8150 method was used to measure the swelling of hydrogels [16]. According to this method, the dry hydrogel is immersed in deionized water for 48 hours at room temperature on a mixer. After swelling, the hydrogel is filtered. The swelling degree is calculated as shown in equation (7).

$$
\text { Swelling degree }=\frac{W_{s S}-W_{d}}{W_{d}} \times 100 \%
$$

where $W_{s s}$ is the weight of the hydrogel in swollen state and $W_{d}$ is the weight of the hydrogel in dry state.

\section{RESULTS AND DISCUSSION}

\section{Characterization of cellulose-acrylamide graft copolymers using FTIR Spectroscopy}

One way to evaluate the success of grafting of acrylamide onto cellulose is by comparing the functionality of the original cellulose with that of the grafted cellulose. For this purpose, the original cellulose and grafted cellulose were characterized using FTIR spectroscopic technique. The FTIR spectra of the original cellulose of rice straw waste and grafted cellulose is presented in Fig. 1.

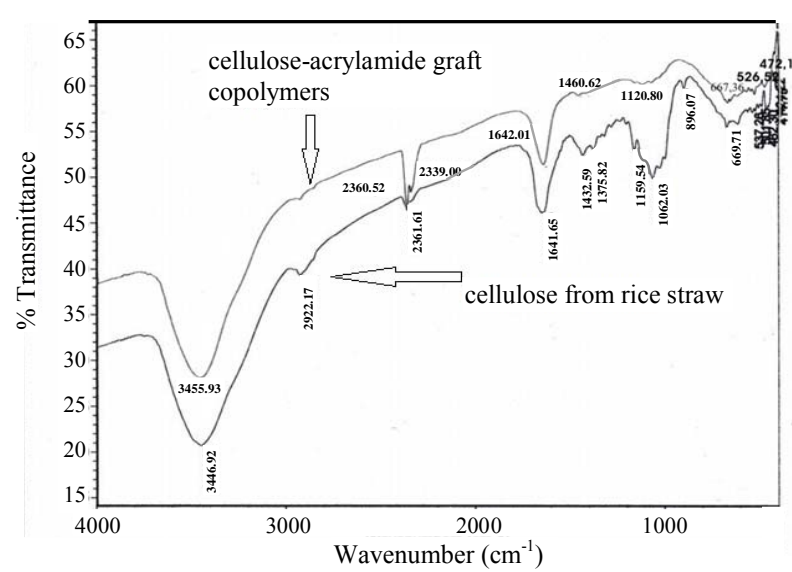

Fig. 1. The FTIR spectra of the original cellulose of rice straw waste and grafted cellulose.

In Fig. 1, the spectrum of the parent cellulose evidently display the presence of $\mathrm{C}-\mathrm{H}$ and $-\mathrm{OH}$ functional group moieties, indicated by the broad absorption band at around $3450 \mathrm{~cm}^{-1}$ and $2920 \mathrm{~cm}^{-1}$ [13]. The spectrum is also marked by the presence of spectral bands in the range of $1000-1150 \mathrm{~cm}^{-1}$, which are characteristic of aloxy group of cellulose. The spectrum of grafted cellulose also shows broader band at $3450 \mathrm{~cm}^{-1}$ and $1642 \mathrm{~cm}^{-1}$. Those bands indicate the $\mathrm{N}-\mathrm{H}$ stretching and the $\mathrm{N}-\mathrm{H}$ bending of the amide bands, which are characteristic of the $-\mathrm{CONH}_{2}$ group present in the acrylamide. The most obvious characteristic of the grafted cellulose spectrum which distinguished it from the spectrum of the original cellulose is the presence of absorption bands at 2339 and $2360 \mathrm{~cm}^{-1}$, which indicate the presence of amide secondary amine group. These changes provide strong evidence of the grafting of acrylamide onto cellulose. 


\section{X-ray diffraction analysis}

X-ray diffractograms of unbleached cellulose, bleached cellulose, grafted unbleached cellulose, and grafted bleached cellulose are presented in Fig. 2 and summarized in Table 1.

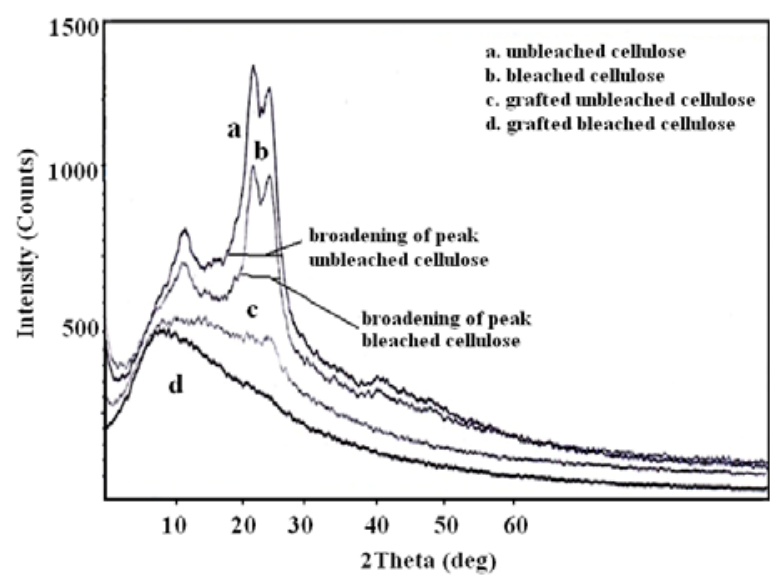

Fig. 2. X-ray diffractograms of cellulose and grafted cellulose.

Table 1. Percentage crystallinity and crystallinity index of cellulose and grafted cellulose

\begin{tabular}{|c|c|c|c|c|}
\hline $\begin{array}{l}\text { Type of } \\
\text { Cellulose }\end{array}$ & $\begin{array}{c}\mathrm{I} \\
22^{\circ}\end{array}$ & $\begin{array}{c}\mathrm{I} \\
18^{\circ}\end{array}$ & $\begin{array}{l}\text { Percentage } \\
\text { crystallinity } \\
(\% \mathrm{Cr})\end{array}$ & $\begin{array}{l}\text { crystallinity } \\
\text { index (C.I.) }\end{array}$ \\
\hline Unbleached & 284 & 30 & 90.45 & 0.8944 \\
\hline $\begin{array}{l}\text { Bleached } \\
\text { with } \mathrm{H}_{2} \mathrm{O}_{2}\end{array}$ & 403 & 72 & 84.84 & 0.8213 \\
\hline $\begin{array}{l}\text { Grafted } \\
\text { unbleached }\end{array}$ & 64 & 14 & 82.05 & 0.7812 \\
\hline $\begin{array}{l}\text { Grafted } \\
\text { bleached }\end{array}$ & 30 & 11 & 73.17 & 0.6333 \\
\hline
\end{tabular}

Compared to the diffraction patterns of extracted cellulose from rice straw, cellulose bleached using $\mathrm{H}_{2} \mathrm{O}_{2}$ show a decrease of intensity and broadening of peak which indicate that the bleaching of cellulose with $\mathrm{H}_{2} \mathrm{O}_{2}$ reduced the crystallinity. The result of XRD analysis (Table 1) showed a decrease in the percentage crystallinity of bleached cellulose compared to that of unbleached cellulose. In bleached cellulose, the consumption of $\mathrm{H}_{2} \mathrm{O}_{2}$ causes the breakage of hydrogen bonds in the crystalline part of cellulose chains, resulting in the reduction of crystallinity.

It is obvious that the X-ray diffraction spectrum of the unbleached cellulose and bleached cellulose have three sharp peaks, but after the cellulose was grafted with acrylamide, it only shows two blunt peaks of reduced intensity. The spectrum also shows that the tails of the peaks, which reflect amorphous part of cellulose, become apparent with grafting. This decrease in intensity indicates that the crystallinity of cellulose- acrylamide graft copolymers decreases. However, the grafted cellulose shows broadening of the peak after grafting, suggesting a convergence of the cellulose towards more disordered system. Indeed, grafting can lead to crosslinking, thus reducing the crystalline structure. The decrease in percentage crystallinity (Table 1) occurs due to the breakdown of hydrogen bonds. $\mathrm{X}$-ray diffraction patterns are visual indicators of the orientation of the cellulose crystals. Crystallinity index gives a quantitative measure of the orientation of the cellulose crystals in the fibers [13]. A lower crystalline index in case of graft co-polymers means poor order of arrangement of cellulose crystals in the fiber, which is due to disorientation of the cellulose crystalline lattice to the fiber axis during grafting. Additionally, grafting could lead to crosslinking, thereby bringing about reduction in the orientation crystalline structure.

\section{Effect of bleaching cellulose on grafting efficiency}

The chemical structure and composition of cellulose can significantly affect grafting. Grafting efficiency of both unbleached and bleached cellulose is shown in Table 2.

Table 2. Effect of bleaching cellulose on grafting efficiency

\begin{tabular}{ll}
\hline Type Cellulose & Grafting efficiency (\%) \\
\hline Grafted unbleached & 73.4999 \\
Grafted bleached & 97.2736 \\
\hline
\end{tabular}

The result shows that $\mathrm{H}_{2} \mathrm{O}_{2}$-bleached cellulose facilitated a higher grafting efficiency than unbleached cellulose. As shown in Table 1, the bleaching treatment decreases the crystallinity of the cellulose. The decrease in crystallization results in an expansion of the amorphous region, which is where most of grafting occurs [5]. In the case of vinyl monomers grafting to cotton fibers cellulose, the cellulose pretreatment with amines increases the viscosity in the amorphous region. This increase in viscocity causes inter- and intra-crystalline swelling which, in turn, improves monomer accesibility, thus increasing the grafting reaction [2]. In addition, the use of $\mathrm{H}_{2} \mathrm{O}_{2}$ in bleaching reduced the lignin content of rice straw. Chemical analysis of rice straw showed that the contents of $\alpha$-cellulose and lignin were $23.48 \%$ and $14.82 \%$, respectively, while after pulping they were $62.30 \%$ and $8.45 \%$. After bleaching they became 89.27 and $0.94 \%$. Hydrogen peroxide reaction with lignin in alkali is illustrated in Fig. 3. 


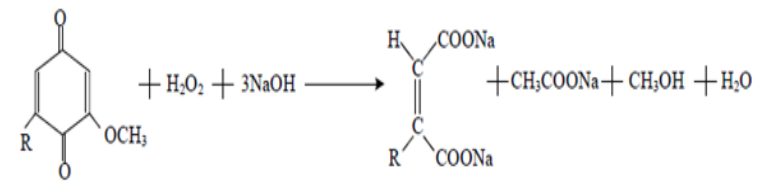

Fig. 3. Mechanism of lignin degradation with $\mathrm{H}_{2} \mathrm{O}_{2}$ [18].

This reaction effectively increases the hydrophilicity of the cellulose backbone and allows the monomer to diffuse easily in the cellulosic structure. The presence of lignin in rice straw affects grafting, since lignin is a good scavenger of radicals. Thus, the bleaching treatment improved grafting efficiency. This phenomenon has also been observed in ethyl acrylate grafting to a sisal fiber system; sisal fiber contains $8 \%$ lignin. The grafting rate is higher when $\mathrm{NaOH}$ is used as a lignin remover [7].

\section{Mechanism and kinetics of cellulose- acrylamide graft copolymerization using gamma radiation}

In simultaneous irradiation, monomer radicals and active sites on the cellulose backbone are simultaneously generated in the same reaction medium. Hence, grafting can be initiated by the active sites on the cellulose backbone. The mechanism of graft copolymerization is quite complex as it involves various stages such as initiation, propagation, and termination which are illustrated in Fig. 4.

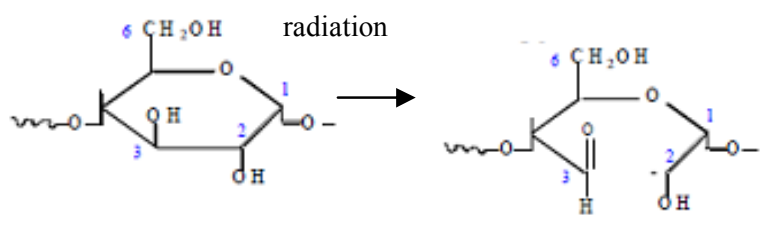

cellulose

cellulose radical (RO')
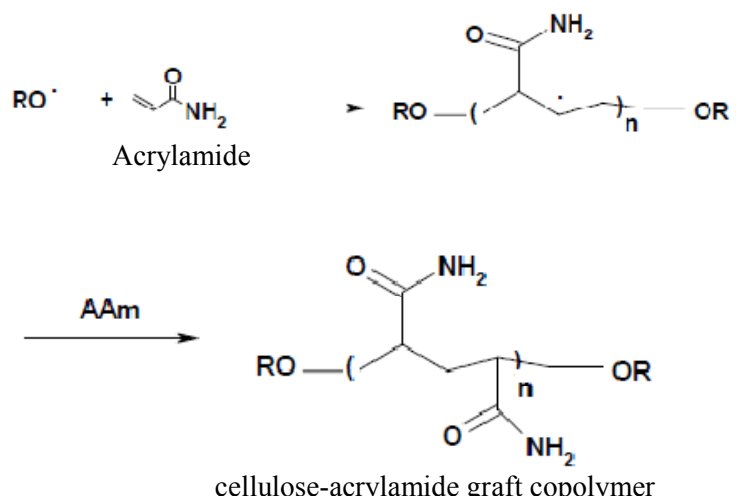

Fig. 4. Mechanism of cellulose-acrylamide graft copolymerization using gamma irradiation.
Irradiation breaks some of $\mathrm{C}_{2}-\mathrm{C}_{3}$ bonds of glucose molecules in the cellulose chain, creating free radical sites on the polymeric backbone. Cellulose radicals, formed during irradiation, add to one side of the acrylamide to form cellulose-acrylamide graft copolymer.

By using a simplified kinetic scheme, the following series of equations for the various steps in a graft polymerization reaction may be written:

Initiation:

$$
\begin{aligned}
& \mathrm{S} \stackrel{\text { radiation }}{\longrightarrow} \mathrm{S} \cdot \\
& \mathrm{S} \cdot \mathrm{M} \stackrel{\mathrm{k}_{\mathrm{i}}}{\longrightarrow} \mathrm{SM} \cdot \\
& \mathrm{R}_{\mathrm{i}}=\mathrm{k}_{\mathrm{i}} \mathrm{C}_{\mathrm{S}} \cdot \mathrm{C}_{\mathrm{M}} \\
& \mathrm{R}_{\mathrm{i}}=\dot{\mathrm{D}} \mathrm{G} \rho_{\text {mix }}
\end{aligned}
$$

Propagation:

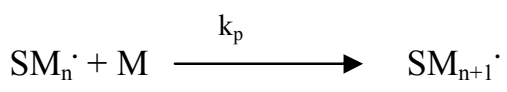

$$
\mathrm{R}_{\mathrm{p}}=\mathrm{k}_{\mathrm{p}} \mathrm{C}_{(\mathrm{SMn} \cdot)} \mathrm{C}_{\mathrm{M}}
$$

Termination:

$$
\begin{aligned}
& \mathrm{SM}_{\mathrm{n}} \cdot+\mathrm{SM}_{\mathrm{n}} \cdot \stackrel{\mathrm{k}_{\mathrm{t}}}{\mathrm{R}_{\mathrm{t}} \quad=\mathrm{k}_{\mathrm{t}}\left(\mathrm{C}_{\mathrm{SMn}} \cdot\right)^{2}} \mathrm{SM}_{\mathrm{n}+\mathrm{n}}
\end{aligned}
$$

where $\mathrm{C}_{\mathrm{S}} \cdot$ is concentration of radical cellulose, $\mathrm{C}_{\mathrm{M}}$ is concentration of acrylamide monomer, $\mathrm{C}_{(\mathrm{SMn} \cdot)}$ is concentration of copolymer radical, $\dot{\mathrm{D}}$ is dose rate, $\mathrm{G}$ is the G-value of cellulose, $\rho_{\text {mix }}$ is the density of cellulose-acrylamide mixture, and $\mathrm{k}_{\mathrm{i}}, \mathrm{k}_{\mathrm{p}}, \mathrm{k}_{\mathrm{t}}$ are rate constants for initiation, propagation, and termination, respectively.

By introducing the conventional steady-state assumption that the rate of change of the concentration of SM- is small compared to its rate of formation, the rate of graft copolymerization is calculated:

$$
R_{p}=\frac{d C_{M}}{d t}=k_{p} C_{M}\left(\frac{R_{i}}{2 k_{t}}\right)^{0.5}
$$

Integration and subsequent rearrangement yields:

$$
\ln \frac{C_{M}}{C_{M 0}}=0.5^{0.5} \frac{k_{p}}{k_{t}^{0.5}} R_{i}^{0.5} \mathrm{t}
$$

The calculations of the kinetic parameters are made based on the assumptions that (1) only the amorphous regions of the polymer are swollen by the monomer and the solvent, (2) the grafting 
reaction takes place only in the amorphous regions of the polymer, (3) the amorphous polymer monomer-solvent system behaves like an ideal solution in that the individual volumes are additive.

The rate constant parameter for graft copolymerization $\left(\mathrm{k}_{\mathrm{p}} / \mathrm{k}_{\mathrm{t}}^{0.5}\right)$ on the dose rate of 3 $\mathrm{kGy} / \mathrm{h}$ can be calculated from the conversion-time curve shown in Fig. 5. The plot of ln (conversion) vs. irradiation time is linear. The slope of line is 0.192 , which suggests that rate constant parameter for cellulose-acrylamide graft copolymerization $\left(\mathrm{k}_{\mathrm{p}} / \mathrm{k}_{\mathrm{t}}{ }^{0.5}\right)$ is $4.9922 \mathrm{l}^{0.5} \cdot \mathrm{mol}^{-0.5} \cdot \mathrm{s}^{-0.5}$.

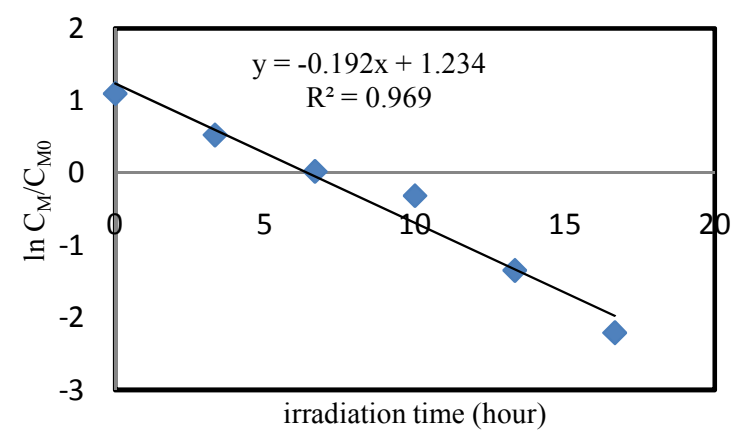

Fig. 5. The plot of $\ln$ (conversion) vs. irradiation time.

\section{Effect of radiation doses on grafting efficiency and gel fraction}

A study on the effects of radiation dose on the grafting efficiency and gel fraction was carried out at room temperature at a dose rate $3 \mathrm{kGy} / \mathrm{h}$. The grafting efficiency and gel fraction were investigated with different irradiation doses ranging from 10 to $50 \mathrm{kGy}$ as shown in Table 3 .

Table 3. Effect of radiation doses on grafting efficiency and gel fraction

\begin{tabular}{ccc}
\hline $\begin{array}{c}\text { Radiation dose } \\
(\mathrm{kGy})\end{array}$ & $\begin{array}{c}\text { Grafting } \\
\text { efficiency }(\%)\end{array}$ & $\begin{array}{c}\text { Gel fraction } \\
(\%)\end{array}$ \\
\hline 10 & 97.2736 & 86.7966 \\
20 & 97.7167 & 88.4939 \\
30 & 98.0362 & 89.6060 \\
40 & 98.0902 & 90.9199 \\
50 & 98.4407 & 94.2304 \\
\hline
\end{tabular}

In Table 3, it can be seen that the grafting efficiency increased quickly with dose at the beginning (11 kGy) and then tended to level off around 30 kGy. The grafting efficiency increased with increasing radiation dose. These trends show good agreement with Abdel et al. [10] upon grafting of rice straw and maize starch onto acrylonitrile. An increase in the total dose enhances the formation of radicals in the reaction mixture of acrylamide monomer, cellulose, and water. All molecules are activated to induce a higher conversion for both homopolymer formation and the grafting reaction. Increasing the total dose reduces the homopolymer content and increases the grafting efficiency, because the high total dose can induce ample active grafting sites on the cellulose backbone for the grafting monomer. Bhardwaj et al. [6] and Abdel et al. [10] have also reported that at higher doses, no more active sites are formed and the constant concentration of the free radicals also gives curvature relationship for grafting percentage with dose. This is due to the combination of some radicals without initiating new grafting sites.

As shown in Table 3, gel fraction increases as radiation dose increases. The trend of increasing gel fraction with radiation dose may be due to the increased number of free radicals on the cellulose chain. Those free radicals can easily form more crosslinks between cellulose chains to create a three-dimensional network. This observation was similar to reported earlier where increasing radiation doses, both for gamma and electron-beam irradiation, could increase gel fractions of cellulose/acrylic acid hydrogels [17].

\section{Effect of radiation doses on crosslink density and swelling degree hydrogels}

Crosslink density is the primary factor affecting the properties of hydrogels such as swelling degree. Effect of radiation dose on the crosslink density and the swelling degree of cellulose-acrylamide graft copolymer hydrogels are showed in Table 4.

Table 4. Effect of radiation doses on crosslink density and swelling degree

\begin{tabular}{ccc}
\hline $\begin{array}{c}\text { Radiation } \\
\text { dose }(\mathrm{kGy})\end{array}$ & $\begin{array}{c}\text { crosslink density } \\
\left(\mathrm{mol} / \mathrm{cm}^{3}\right)\end{array}$ & $\begin{array}{c}\text { Swelling degree } \\
(\%)\end{array}$ \\
\hline 10 & 0.0041589 & 1288.2604 \\
20 & 0.0013515 & 1509.6042 \\
30 & 0.0083028 & 860.7512 \\
40 & 0.0049244 & 1189.1900 \\
50 & 0.0054941 & 1086.7500 \\
\hline
\end{tabular}

Table 4 reveals that crosslink density decreases as radiation dose increases from 10 to $20 \mathrm{kGy}$. However, as the radiation dose increases again to $30 \mathrm{kGy}$, the homogeneous crosslink density increases. A possible explanation is as follows. An increase in radiation dose may increase the number of free radicals on the cellulose chain. In turn,this causes the formation of more crosslinks between cellulose chains. However, after reaching a saturation point or maximum crosslink density, which appears to be about $30 \mathrm{kGy}$ in this case, the 
irradiated cellulose-acrylamide is not significantly affected by further radiation dose increase. It can thus be said that the optimum radiation dose is about $30 \mathrm{kGy}$. This saturation probably explains some deterioration of cellulose. The same trend was observed in radiation grafting of vinyl and alkyl monomer into cotton fiber cellulose; in that case, increasing the irradiation dose may result in the degradation of the already crosslinked cellulose, and a slight reduction in crosslink density was observed [2,3].

Table 4 show that swelling is increased the increasing radiation dose from 10 to $20 \mathrm{kGy}$. It was found that the swelling degree of the hydrogel decreases by increasing the total irradiation dose from 20 to $30 \mathrm{kGy}$. These results could be explained in terms of crosslink density which shown in Fig. 6.

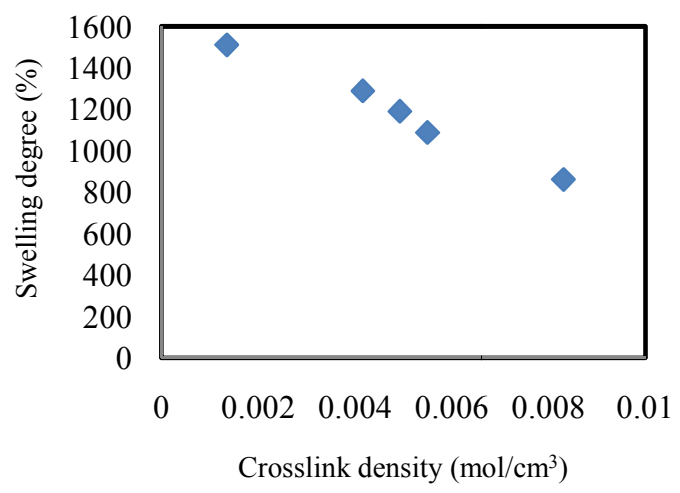

Fig. 6. Effect of crosslink density on swelling degree.

The swelling of the hydrogels linearly decreases as crosslink density increases. The increment in the crosslink density reduces the free volume available for swelling by increasing the tightness of the network structure. Gao [7] and Nagasawa et al. [16] also reported that higher irradiation doses could decrease the water absorbency of graft copolymers. Swelling is a result of balance between two forces, namely osmotic force and dispersing force. Osmotic force pushes water into the polymer network whereas dispersing force exerted by the polymer chains resist it $[7,9,16]$. Increases in crosslink density enhance the dispersing force. Hence, with the increased crosslinked density, less scope is available for free water to enter the vacant spaces of the crosslinking network.

\section{CONCLUSION}

Rice straw cellulose has been successfully modified through graft copolymerization with acrylamide by using gamma radiation as an efficient free radical initiators. FTIR and XRD analyses showed that acrylamide had been grafted onto cellulose successfully. XRD confirmed the reduction in percentage crystallinity $(\% \mathrm{Cr})$ and crystallinity index (C.I.) with grafting process. The reaction scheme and graft copolymerization was kinetically studied. It was found that the rate constant parameter for cellulose-acrylamide graft copolymerization $\left(\mathrm{k}_{\mathrm{p}} / \mathrm{k}_{\mathrm{t}}^{0.5}\right)$ is $4.9922 \mathrm{l}^{0.5} \cdot \mathrm{mol}^{-}$ ${ }_{0.5} . \mathrm{s}^{-0.5}$. The grafting efficiency was increased by bleaching the cellulose using $\mathrm{H}_{2} \mathrm{O}_{2}$. The higher the irradiation dose, the higher the grafting efficiency and the gel fraction of celluloseacrylamide hydrogels. Crosslink density first decreases and then increases with increasing radiation dose; however, the swelling degree shows the opposite trend. The radiation induced graft copolymer shows excellent swelling behavior, indicating that the cellulose graft copolymer can be used in applications where swelling is an important criteria.

\section{ACKNOWLEDGMENT}

The authors are grateful for the financial support of Indonesia Toray Science Foundation (ITSF) and The State Ministry of Research and Technology for Doctoral scholarship program. The author would like to thanks to Kartini Megasari, Sukmawati Teguh Rahayu and Sri Nuryani for contribution help to this research activity. Special thanks also to Prof. Gill Garnier from Australian Pulp and Paper Institute, Monash University for insightful comments and for many motivating discussions.

\section{REFERENCES}

1. J. Chen, P. Sun, Z.T. Liu and Z.W. Liu, Cellulose 16 (2009) 1133.

2. M.I. Mondal, Y. Uraki, M. Ubukata and K. Itoyama, Cellulose 15 (2008) 633.

3. S. Liu and G. Sun, Carbohydrate Polymers 71 (2008) 615.

4. K.M. Mostafa, J. Appl. Sci. 5 (2005) 528.

5. K.C. Gupta and K. Khandekar, J. Appl. Polym. Sci. 101 (2006) 116.

6. Y.K. Bhardwaj, V. Kumar, A. Acharya and S. Sabharwal, IAEA-TECDOC-1465, IAEA, Vienna (2005) 87. 
7. D. Gao, Superabsorbent Polymer Composite (SAPC) Materials and their Industrial and High-Tech Applications, Ph.D. Dissertation, Der Technische Universität Bergakademie Freiberg (2003).

8. S.H. Hossein, Research J. Pharm., Biol. and Chem. Sci. 2 (2011) 446.

9. A. Hekmat, A. Barati, E.V. Frahani and A. Afraz, Eng. and Tech. 56 (2009) 97.

10. A. Abdel, Y.H Gad and A.M. Dessouki, J. Hazard. Mater. 129 (2006) 204.

11. R. Bongiovanni, E. Zeno, A. Pollicino, P.M Serafini and C. Tonelli, Cellulose 18 (2010) 118.

12. N. Terinte, R. Ibbet and K.C. Schuster,
Lenzinger Berichte 89 (2011) 122.

13. M. Mohkami and M. Talaeipour, BioResources 6 (2011) 1990.

14. P.J. Flory, Principles of polymer chemistry, Cornell University Press, New York (1953) 579.

15. V. Sekkar, S. Gopalakrishnan and K.A. Devi, Eur. Polym. J. 39 (2003) 1282.

16. N. Nagasawa, T. Yagi, T. Kume and F. Yoshii, Carbohydr. Polym. 58 (2004) 110.

17. M.C. Amin, N. Ahmad, N.Halib and I. Ahmad, Carbohydr. Polym. 88 (2012) 470.

18. V.T. Selig, M.E. Himmel and S.R. Decker, Appl. Biochem. Biotechnol. 155 (2009) 399. 